M. Coggia observed that on the approach of the shadow's edge, at $12 \mathrm{~h} .45 \mathrm{~m}$. (Marseilles M.T.), Plato took on a red tint, which became redder until, at $12 \mathrm{~h} .50 \mathrm{~m}$. , it appeared like glowing charcoal.

Mr. J. H. Elgie writes that, according to his observations, at Leeds, the eclipse was a "light" one; although at its first encroachment the "shadow was dead black, when the disc was fully eclipsed many features could be perceived by the naked eye. The shadow was first seen, without a telescope, at about Ir.45 p.m. Mr. Elgie also directs attention to a curious glow in the northern heavens throughout the night, almost suggestive of an auroral display.

The Photoheliometer.- In No. 4, vol. xxix., of the Astrophysical Journal (May, p. 313), Prof. Poor describes, and gives the results of, some experiments carried out at the Yerkes Observatory in order to determine the feasibility of employing the heliometer method in the endeavour to detect differences in the solar diameters, polar and rquatorial, at different epochs.

Photographs were obtained with two lenses of 2 inches aperture and 25 feet focal length, mounted side by side in (h) same cell, so as to give overlapping images of the sun. with the film side of the plate turned away from the object, so that when compared, film to film, with normal negatives of a different epoch, changes occurring during the interval might be readily detected.

So far these have only been used for light changes, and not for changes of position produced by proper motion and parallax. 'Tests recently carried out by Dr. Schlesinger at the Allegheny Observatory show, however, that such plates may safely be used for determinations of changes of position, for observing through the glass has, in the plates tested, produced no serious error, the mean value of the possible error being of the order of $0.001 \mathrm{~mm}$. On such plates, taken at an interval of ten years, a proper motion of $0.025^{\prime \prime}$ per annum could be readily detected (Publications of the Allegheny Observatory, vol. i., No. 14).

\section{THE NEW INSTITUTE OF PHYSIOLOGY AT UNIVERSITY COLLEGE, LONDON.}

$\mathrm{BY}$ the completion of the Physiological Institute at University College, London, which has been erected within the past twelve months upon the site of the playground of University College School, the University of

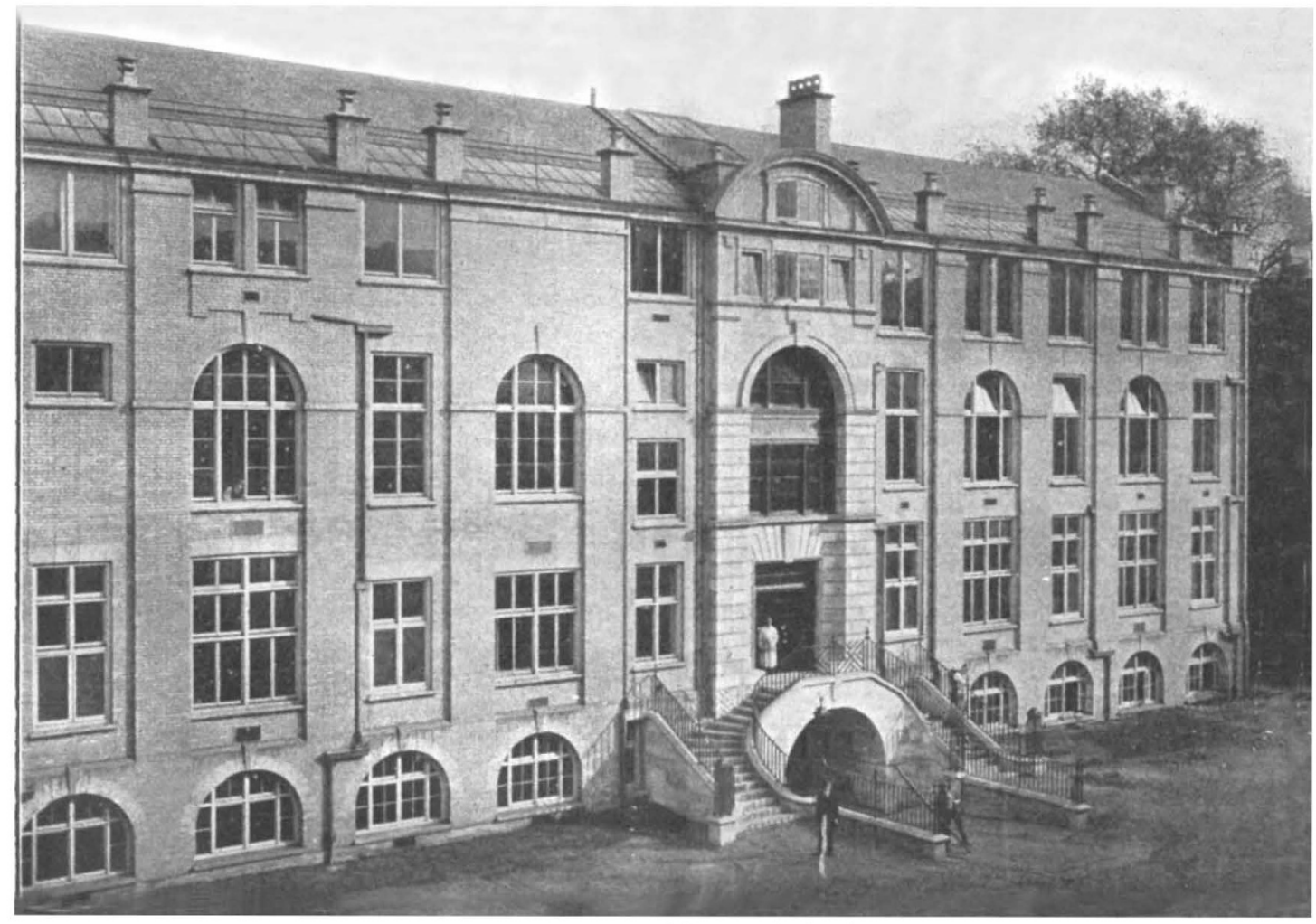

FiG. 1.-Institute of Physiology, north elevation.

Then two methods of measurement were tried, one in which the diameter passing through the centres of the two images was determined directly, the other in which the solar radius was determined from measurements of the chord common to the two overlapping images. Prof. Poor discusses both methods, and concludes that the second will give the better results. Finally, he concludes that for his researches the photoheliometer is better than the direct photographic method, and gives some practical working hints, e.g. Ivet plates should be used on account of the sharper, clearer images they give. A series of six trial plates, taken during October and November, 1907, gave a mean excess of equatorial over polar radius of $0.95^{\prime \prime}$.

The ERrors of Position of Images photographed THROUGH Glass.-For some time past photographs of star areas have been taken at Harvard College Observatory
London possesses what is probably the finest laboratory of its kind in the country, and one which is perfectly equipped both for teaching all branches of physiology and for the pursuit of original research work. The erection of this institute marks an epoch, not only in the history of the re-constituted University of London, but in the development and advancement of the British school of physiology, a school which was practically non-existent a few decades ago, when nearly all research in this subject was carried out in the laboratories of France and Germany.

It is a matter for congratulation to those who have been instrumental in founding this institute that the subject of physiology is to be both taught and advanced by original work, for in the creation of this science University College may fairly claim to have played a

No. 2069, VOL. 8o] 
most important part. British physiologists have long recognised the paramount influence exerted by William Sharpey during his tenure of the professorship of anatomy and physiology, which lasted from 1837 until his retirement in 1873 , and the men who came under his influence may be considered to have demonstrated by their work the methods and lines of research along which physiology was in the future to be developed if this science was to take rank with allied experimental sciences and cease to be a subject overladen with speculative views. Michael Foster, Burdon-Sanderson and Newell Martin all acquired their physiological training in the laboratory of University College, and each succeeded in establishing a school of physiology in Cambridge, Oxford, and Baltimore. The study of this science, which is now pursued so successfully in no less than thirteen universities in Great-Britain, may indeed be said to have spread over England from Sharpey's laboratory, for a considerable number of those who are at present furthering the progress of experimental medicine received a part, and in some cases the whole, of their training in the physiological laboratory of the college.

The institute of physiology is to be part of an institute of medical sciences which shall include anatomy and pharmacology. The erection of this was possible owing to the generous donations of $\mathrm{Dr}$. Aders Plimmer and Dr. Ludwig. Mond, while the expenses of equipment have been met partly by subscriptions and partly by a legacy left by the late Mr. Thomas Webb for the purposes of research. The building is from the designs of Prof. F. M. Simpson, who has admirably carried out the arrangement of the various special laboratories and rooms which Prof. Starling, to whose energy and initiative the institute is really due, has planned and suggested, and in this he has introduced all the most recent improvements that experience gained by visits to other laboratories in this country and abroad has shown are of such importance for the efficient study of physiology.

The development of organic chemistry, and with this of physiological chemistry, has been so great in recent years that the whole ground floor of the building is entirely devoted to rooms and research laboratories in this subject. Owing to the foresight of Prof. Starling, ample provision has been made for the present and future requirements of this part of physiology, which has virtually become a branch of physiology somewhat sharply separated off from purely experimental work. That the solution of many problems must ultimately lie in the hands of those physiologists who are highly trained chemists and physicists is an obvious truth, and in the institute of physiology the importance of this branch of study has been kept in view.

The large laboratory in the rooms, such as a balance room, students. Separat distillation room and one for carrying out four combustions at the same time, occupy part of the east wing. Several other rooms, which can be completely darkened, and are furnished with first-rate apparatus for the purpose, are devoted to special purposes, and in these work can be carried out which requires the use of the spectroscope, polarimeter, or spectrophotometer. A large refrigerating chamber and a "FabrikRaum "for the working up of material on a large scale are also provided in the basement. Rooms for experimental physiology and the library occupy the first floor, on which there is also a lecture theatre with seating accommodation for 200 students. A large students' room for histology and experimental physiology occupies the whole of the west wing of the second floor, while the upper wing comprises a demonstration theatre, so arranged that forty students can abtain a full view of any experiment, and a suite of four rooms devoted to the aseptic department.

NO. 2069, VOL. 8o]
On June 18 the institute was formally declared open by Mr. Haldane. Among those who received him were the following:-the Vice-Chancellor (Prof. M. J. M. Hill, F.R.S.), the chairman of the college (Lord Reay, G.C.S.I.), the president of the Royal Society (Sir Archibald Geikie, K.C.B.), the president of the Royal College VAIVIERSTIY OIF LOADOA. VAIVIERSITY COLLIEGE. AIEW PHYSIOLOGY $I A S T I T V T E$.



SECCOAD $\mathbb{P} L O Q \mathbb{R} \mathbb{R} \mathbb{R} A$.

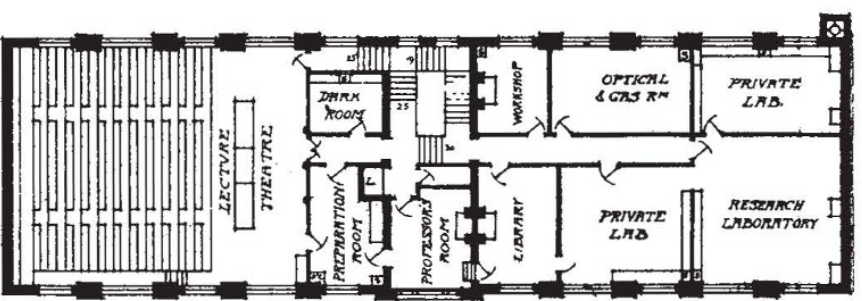

FIIRST FLOOR IPLIAIA.

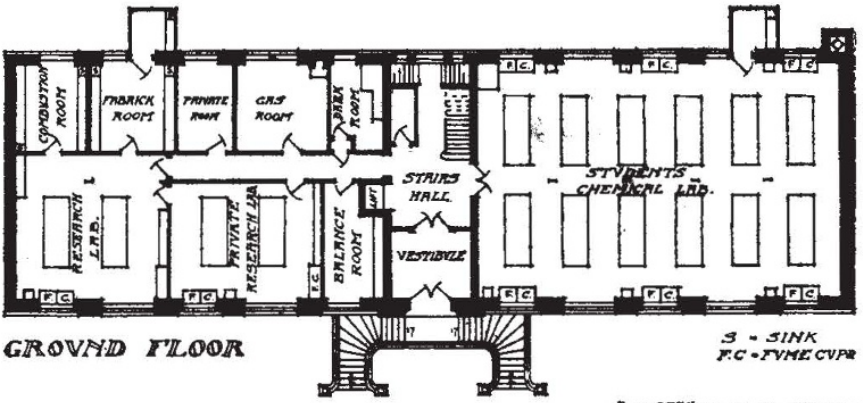



Fig. 2.-Plan of the arrangement of laboratories on the basement and floors of the Institute.

of Physicians (Sir R. Douglas Powell, Bart., K.C.V.O.) the president of the Royal College of Surgeons (Mr. Henry Morris), the president of the Royal Society of Medicine (Sir William Church, Bart., K.C.B.), the principal (Dr. H. A. Miers, F.R.S.), the provost of University College (Dr. T. Gregory Foster), the treasurer of University 
College (Sir Felix Schuster, Bart.), the dean of the faculty of science (Prof. Millar Thomson, F.R.S.), the dean of the faculty of medicine (Prof. Sidney Martin, F.R.S.), the chairman of the military education committee (Prof. D. S. Capper), the secretary of the Royal Society (Dr. J. Rose Bradford), the dean of the college faculty of medical sciences (Prof. G. D. Thane), and the Jodrell professor of physiology (Prof. E. H. Starling, F.R.S.).

In his address, given to an audience which filled the lecture theatre, Mr. Haldane outlined the gradual growth of the facilities for the highest education in science which has been witnessed in this country during the past twenty years, a growth which, he pointed out, has completely upset the somewhat pessimistic prognostications of Matthew Arnold, who, as an authority on this question, expressed the opinion that any extension of the facilities offered by the older universities was most improbable. It is, however, only fair to state that it was with reference to the arts rather than the science side of education that he took this somewhat gloomy view of affairs. Mr. Haldane, who admitted that he appeared to others to be obsessed with a passion for organisation, while avoiding some of those debatable questions which were so intimately bound up with the work of many of those who listened to him, indicated with exceptional lucidity that if any civilised country is to continue to hold its own, abundant facilities must exist for the pursuit of knowledge by research, and that it was unnecessary to support this by arguments must have been apparent to his audience. That in the institute of physiology full provision for the highest teaching in this subject is available, not only for our own countrymen, but for those from American and foreign universities, was also indicated by Prof. Starling, who, after speaking of the international bonds of friendship which the study of science does so much to foster, made clear the truism that in such places as this institute the real work is carried out which supplies the medical profession throughout the world with the knowledge requisite for their successful treatment of disease. Those who have the best interests of their profession at heart know that this is so.

The erection of this institute is largely due to Prof. Starling, whose ideas have been carried out in this build ing, which, with its admirable arrangements for work and excellent equipment, farms a great addition to the opportunities for teaching research offered by the University of London.

\section{THE INVESTIGATION OF GASEOUS EXPLOSIONS. ${ }^{1}$}

$\mathrm{A}^{\mathrm{T}}$ the Leicester meeting (1907) of the British Association it was suggested that the investigation of gaseous explosions was a matter which might suitably form the work of a committee of Section G (Engineering), and although the subject is chiefly of interest to engineers because of its bearing on the theory of the internal-combustion engine, the committee appointed has not confined its attention to questions of a purely practical character, but has discussed many questions of scientific importance which might properly be considered of interest to the physical and chemical sections.

In order that the labours of the committee might lead to some result within a reasonable time, the work so far undertaken has been mainly a critical examination and discussion of the results of previous investigations with a view to further research, and to this end the report cliscusses, at some length, various interesting and important matters which in their opinion require further investiga-

The essential feature in the operation of an internalcombustion engine is the explosion of a mixture of inflammable gases by which is formed a complex mixture of nitrogen, carbon dioxide, steam and oxygen, and the performance of the engine depends primarily on the changes of pressure and volume of the gas, and is only

1 First Report of the British Association Committee appointed for the Investigation of Gaseous Explosions, with Special Reference to Tempera. ture. Presented at the Dublin meeting, 1908.

NO. 2069, VOL. 8o] influenced in a slight degree by the nature of the chemical changes and the velocity with which these take place.

The problem is mainly that of the behaviour of gases at high temperatures, and the properties of such gases are completely defined when the relation between pressure and volume at constant temperature is known, and the internal energy is given as a function of the temperature and the density. The first relation is substantially that expressed by Boyle's law for all gases with which we have to deal, while it is sufficient for the present if the internal energy can be expressed as a function of the temperature, and it is with this internal-energy function that the report chiefly deals.

Measurements of the internal energy have been carried out, as a rule, with the gas at either constant pressure or at constant volume, and the experiments of Holborn and Austin and Holborn and Henning on air, steam, and $\mathrm{CO}_{3}$, at constant pressure, have shown that, with increasing temperature, there is an increase in the internal energy, which is probably not a linear function of the temperature. The principal part of our knowledge of the behaviour of gases at high temperatures has, however, been obtained by explosion experiments in closed vessels, and if we could accurately make the necessary corrections for deducing from the observed pressures in a real explosion the pressures reached in an ideal one, we could obtain an accurate value of the internal-energy function.

The difficulties of making corrections due to the disturbing influences are very great, but in spite of this the study of explosion pressures has been mainly responsible for the knowledge we possess of the energy function, and the committee therefore considers this method and the possible inaccuräcies in detail.

If the calorific value of a mixture before combustion is known, and the heat lost at any time after the explosion is determinate; the remaining disturbing causes are due to the want of thermal and chemical equilibrium, and possibly to the motion of the gases; we must therefore determine what effect all these disturbing factors have in altering the observed pressure from which the temperature is inferred.

Much of the loss of heat appears to be due to direct conduction to the walls of the enclosing vessel, but it is probable that loss by radiation is also important, as in some of the experiments considered, where loss by conduction was imp obable, the pressures obtained were consistent with a considerable loss by radiation.

The thermal state of the exploded charge has been the subject of much investigation. In a closed vessel the combustion at the point of ignition is completed before any appreciable rise of pressure takes place, and the flame spreads outwards at a velocity which has been estimated at from 120 to 150 centimetres per second, accompanied by a rise of pressure due to the progress of the combustion. The flame, therefore, spreads in an increasingly denser gas, and since the rise of temperature on explosion is nearly independent of the pressures before ignition, the temperatures attained at those places which are reached last by the flame are much below the mean owing to the final adiabatic compression and consequent rise in temperature of the already ignited gas.

At the moment of maximum pressure the temperature varies enormously, as is shown by the measurements of Hopkinson in an approximately cylindrical vessel of 6 cubic feet capacity, where, with a mean temperature of $1600^{\circ} \mathrm{C}$., the maximum temperature at the point of ignition was $1900^{\circ}$ C., and near the walls about $1200^{\circ} \mathrm{C}$.

The temperature of the wall surface in such a vessel is much lower, and in a gas engine, working under normal conditions with a water-jacketed cylinder, the usual temperature is about $200^{\circ} \mathrm{C}$., with a fluctuation of rarely more than $10^{\circ} \mathrm{C}$. during the whole cycle. Up to the time of maximum pressure there appears to be no appreciable equalisation of temperature, but convection and conduction rapidly obliterate these initial differences. If the specific heat of the gas were constant, the attainment of thermal equilibrium would make no difference to the 